\title{
QTc interval prolongation in HIV-infected patients: a case-control study by 24 -hour Holter ECG recording
}

Alessandra Fiorentini ${ }^{1}$, Nicola Petrosillo ${ }^{2}$, Angelo Di Stefano ${ }^{3}$, Stefania Cicalini ${ }^{2}$, Laura Borgognoni ${ }^{3}$, Evangelo Boumis ${ }^{2}$, Luigi Tubani ${ }^{3}$ and Pierangelo Chinello ${ }^{2^{*}}$

\begin{abstract}
Background: Aim of the study was to assess QTc interval by a 24-hour ECG recording in a group of HIV-infected individuals with a basal prolonged QTc. The risk factors associated with QTc prolongation and the indices of cardiovascular autonomic control were also evaluated.

Methods: A case-control study was performed using as cases 32 HIV-infected patients with prolonged (>440 msec) QTc interval as assessed by Holter ECG, and as controls 64 HIV-infected subjects with normal QTc interval. Autonomic function was evaluated by heart rate variability analysis during 24-hour recording.

Results: Duration of HIV disease was significantly longer among cases than among controls $(p=0.04)$. Waist/hip ratio was also higher among cases than among controls $(p=0.05)$. Frequency domain analysis showed the absence of physiologic decrease of low frequency (LF) in the night period in both cases and controls. The LF night in cases showed a statistically significant reduction when compared with controls $(p=0.007)$.

Conclusions: In our study group, QTc interval prolongation was associated with a longer duration of HIV infection and with a greater waist/hip ratio. HIV patients with QTC interval prolongation and with a longer duration of HIV infection were more likely to have an impairment of parasympathetic and sympathetic cardiac component.
\end{abstract}

Keywords: Cardiac autonomic function, HIV, Holter ECG, QTc interval

\section{Background}

QTc interval prolongation is an electrocardiographic abnormality that may cause severe arrhythmias including torsades de pointes and ventricular fibrillation. An increased prevalence of QTc interval prolongation and a longer QTc interval have been described among HIVinfected patients when compared to HIV-negative subjects [1-4]. QTc interval prolongation in HIV-positive patients has been associated with several drugs [5-14], with autonomic dysfunction due to HIV-associated neuropathy [15,16], and with HCV coinfection [3]. The duration of ventricular repolarization can change during the day [17-19]; aim of the study was to assess QTc interval by a 24-hour ECG recording in a group of HIV-infected

\footnotetext{
*Correspondence: pierangelo.chinello@inmi.it

${ }^{2}$ Second Infectious Diseases Unit, National Institute for Infectious Diseases "L. Spallanzani", via Portuense 292, Rome 00149, Italy

Full list of author information is available at the end of the article
}

individuals who presented a basal prolonged QTc. The risk factors associated with QTc prolongation and the indices of cardiovascular autonomic control were also evaluated.

\section{Methods}

In the first phase of the study, 27 consecutive HIVinfected patients with known prolonged QTc interval (group I) as assessed by standard ECG recording, and 54 HIV-positive patients with normal QTc interval (group II) matched 1:2 with group I individuals by gender and age ( \pm 5 years) underwent 24-hour Holter ECG recording. QTc interval assessed by standard ECG recording was defined as prolonged when $>440 \mathrm{msec}[20,21]$.

In the second phase of the study, a "nested" case-control study was performed using as cases the 32 patients of both group I and II with prolonged QTc interval as assessed by Holter ECG, and as controls (1:2) 64 HIV infected subjects with normal QTc interval as assessed by standard and

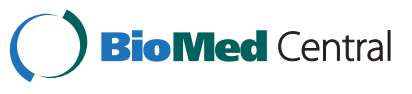


Holter ECG, matched by gender and age ( \pm 5 years). Forty patients came from the original group II, and 24 were consecutive HIV-infected patients with normal QTc interval at standard and Holter ECG recording. The algorithm of the study is illustrated in Figure 1. QTc interval assessed by Holter ECG recording was defined as prolonged when its mean value was $>440 \mathrm{msec}$.

For each subject the following data were ascertained: demographic features; risk factors for HIV infection; HIV clinical group according to the Centers for Disease Control and Prevention (CDC), Atlanta, classification; ongoing therapy and prophylaxis; excessive alcohol intake; cardiologic risk factors including diabetes, hypertension, dyslipidemia, smoking habits, and family history; CD4+ lymphocytes count, HIV viraemia and the results of the main haematochemical tests including glycaemia, serum electrolytes, total cholesterol, high-density lipoprotein-cholesterol, low-density lipoprotein-cholesterol, and triglycerides. Hypertension was defined as a blood pressure $\geq 140 \mathrm{mmHg}$ systolic or $\geq 90 \mathrm{mmHg}$ diastolic or current use of antihypertensive medication [22]. Hypercholesterolaemia was defined as a serum total cholesterol level $\geq 200 \mathrm{mg} / \mathrm{dL}$, hypertriglyceridaemia as a serum triglyceride level $\geq 200 \mathrm{mg} / \mathrm{dL}$, and diabetes as fasting blood glucose of $126 \mathrm{mg} / \mathrm{dL}$ or greater [22]. Obesity was defined as a body mass index $>30 \mathrm{~kg} / \mathrm{m}^{2}$. Excessive alcohol intake was defined as follows: for women and persons $>65$ years of age, $>7$ standard drinks per week or $>3$ drinks per occasion; for men $\leq 65$ years of age, $>14$ standard drinks per week or $>4$ drinks per occasion; a standard drink is approximately 12 to $14 \mathrm{~g}$ of ethanol [23].
All subjects, during ECG Holter registration, spent on average $8 \mathrm{~h}$ in bed, from 11 p.m. to 7 a.m. ECG Holter was analysed for 24 hours, at 10 minutes interval. Artificial data and arrhythmic events were excluded. Autonomic nervous system function was evaluated by heart rate variability (HRV) analysis during 24-hour ECG recording. All Holter recordings were performed using a three-channel recorder. Cardiovascular variability was analysed following the recommendations of the Task Force of the European Society of Cardiology and the North American Society of Pacing and Electrophysiology [24].

Spectral estimated of R-R interval were obtained from stationary regions free of ectopic beats and technical artifacts. The standard deviation of normal-to-normal RR intervals [SDNN (ms), correlated with total autonomic activity] and the square root of the mean of the sum of the squares of differences between adjacent $\mathrm{NN}$ intervals [RMS-SD (ms), correlated with parasympathetic system] were calculated and were divided in two period: night ( $0 \mathrm{am}-6 \mathrm{am})$ and day $(7 \mathrm{am}-11 \mathrm{pm})$. Fast Fourier Transform was used to obtain power spectral estimates of $\mathrm{HRV}$; total power in the frequency range $(0-0.40 \mathrm{~Hz})$ was divided into: very low frequency (VLF: < 0.04 Hz), low frequency (LF: 0.04-0.15 Hz, modulated by sympathetic system), and high frequency (HF: $0.15-0.40 \mathrm{~Hz}$, mediated by parasympathetic system). The integral under respective power density functions were measured and were expressed in absolute units $\left(\mathrm{ms}^{2} / \mathrm{Hz}\right)$. Each spectral component was presented in normalized units (n.u.) by dividing LF or HF by total power minus the very low frequency (LF or HF/total power - VLF). LF/HF ratio, considered an index of

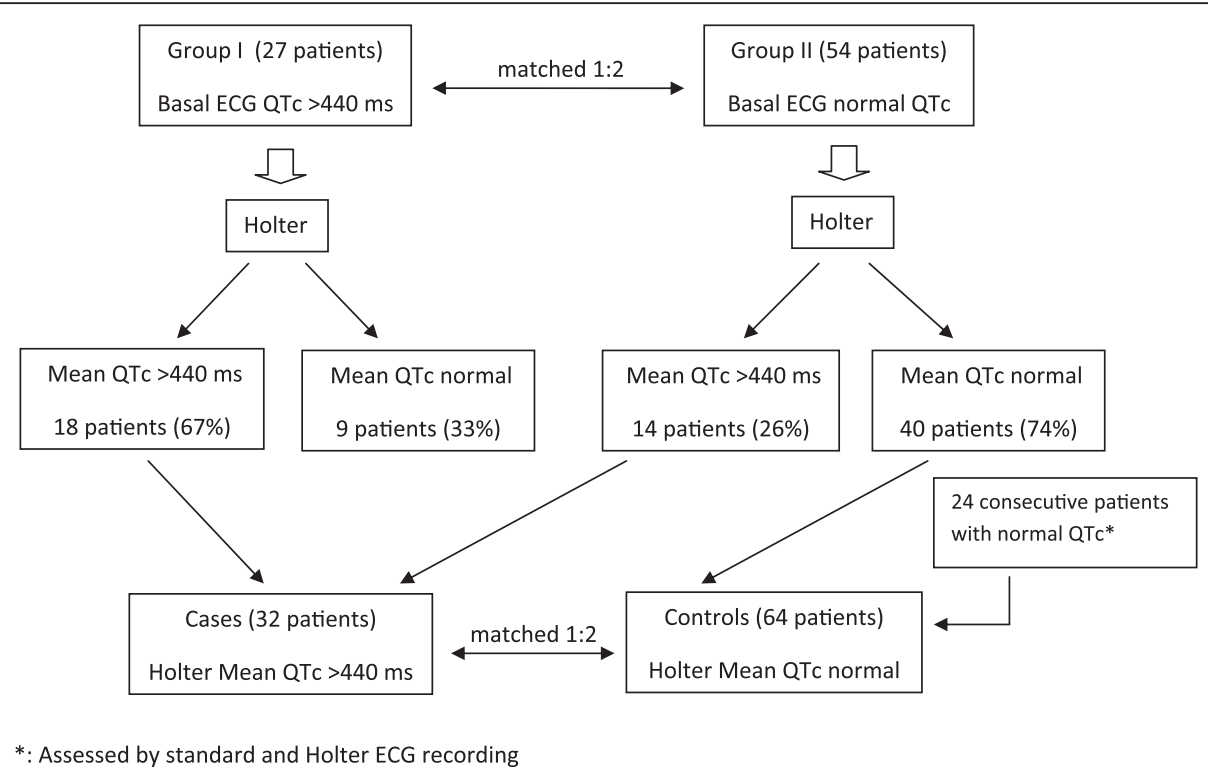

Figure 1 Algorithm of the study. 
cardiac sympathetic/parasympathetic tone balance, was also calculated. We examined HRV during 24 hours (total HRV), in the night time $(0 \mathrm{am}-6 \mathrm{am})$ and in the day time (7 am -11 pm).

The program calculates the QT interval from beginning of QRS to the end of the $\mathrm{T}$ wave. The end of the $\mathrm{T}$ wave was defined as the point of maximal change in the slope as the $\mathrm{T}$ wave merges with the baseline. QT interval was corrected for heart rate by calculating QTc. QTc was calculated by Bazett's equation [QTc $=\mathrm{QT} / \mathrm{RR}^{1 / 2}$ ] and was controlled by at least two physicians (L.T., A.F., A.D.S, and L.B.).

Data analyses were performed by Del Mar Avionics Accuplus 363, Irvine California, USA. In ten healthy subjects reproducibility was evaluated by means of the interclass correlation coefficient (ICC) comparing baseline values with the results obtained at the fourth week ICC was more $>0.7$ for HRV.

Informed consent was obtained from all participants; all the investigations were performed in accordance with the principles of the Declaration of Helsinki. The research was approved by the Ethics Committee of "L. Spallanzani" National Institute for Infectious Diseases, Rome (Italy).

Statistical analysis was performed by SPSS 13.0 (SPSS Inc., Chicago, IL, U.S.A.) for Windows XP. Correlation between discrete and continuous variables were assessed by chi-square ant $\mathrm{t}$-student tests, respectively. Parametric data were expressed as means \pm standard deviation. A $p \leq 0.05$ was considered as statistically significant.

\section{Results}

Twenty-seven consecutive HIV-infected patients (group I) with known prolonged QTc interval (mean $464 \pm 23$ $\mathrm{msec}$ ) assessed by ECG recording at a previous study [25] underwent 24-hour Holter ECG recording. Twentyone of them were males, their mean age was $46.6 \pm 9.5$ years, and they were HIV positive since $10.5 \pm 6.4$ years. Eighteen out of 27 patients (67\%) had QTc interval prolongation confirmed by Holter ECG recording, while 9/27 (33\%) showed a normal QTc interval at Holter ECG.

The 54 patients of group II had a normal QTc interval (mean $406 \pm 20 \mathrm{msec}$ ) assessed by standard ECG; they were 42 males and 12 females, HIV positive since 8.6 \pm 6.8 years, with a mean age of $46 \pm 9.2$ years. Fourty of them $(74 \%)$ had a normal QTc interval confirmed by Holter ECG recording, while 14/54 (26\%) showed a prolonged QTc interval at Holter ECG.

Overall, 32 patients from both group I and II had a prolonged QTc interval (mean $475 \pm 33 \mathrm{~ms}$ ) assessed by Holter ECG recording and were considered cases. They were matched by gender and age ( \pm 5 years) with 64 controls exhibiting a normal QTc interval assessed by Holter ECG. The main demographic and clinical features of cases and controls are described in Table 1. Neither cases nor controls complained of angina or dyspnoea. Thirteen patients among cases (41\%) and 17 among controls $(26 \%)$ presented ectopic ventricular beats $(\mathrm{p}=0.2)$; 14 patients among cases (44\%) and 30 among controls (47\%) presented ectopic supraventricular beats $(\mathrm{p}=0.9)$. Duration of HIV disease was significantly longer among cases than among controls (10.9 \pm 7.1 years vs $7.8 \pm 6.4$ years; $\mathrm{p}=0.04)$. Cases were more frequently alcohol abusers than controls, although at a not statistically significant level (16\% vs 5\%; OR 3.77, 95\% C.I. 0.71-21.74; $\mathrm{p}=0.1)$. Waist/hip ratio was higher among cases than among controls $(0.93 \pm 0.07$ vs $0.90 \pm 0.07 ; \mathrm{p}=0.05)$. Among cases, after a mean follow-up of $4.8 \pm 0.9$ years 5 patients resulted dead and 27 were still alive; among controls, after a mean follow-up of $4.1 \pm 1.1$ years 2 patients resulted dead and 62 were still alive $(\mathrm{p}=0.04)$.

Antiretroviral drugs were not associated with QTc prolongation at a statistically significant level (Table 2). However, patients treated with zidovudine (AZT) presented QTc prolongation more frequently than patients not treated with AZT (34\% vs 19\%; OR 2.27 and $95 \%$ C. I. 0.78-6.62; $\mathrm{p}=0.15)$. Moreover, patients receiving emtricitabine (FTC) were less likely to have a QTc prolongation than patients not receiving FTC (12\% vs $31 \%$; OR 0.31 and $95 \%$ C.I. $0.08-1.12$; $\mathrm{p}=0.08$ ).

Table 3 illustrates the indices of cardiovascular autonomic control among cases and controls. Time domain analysis showed a reduction of total SDNN in cases and controls versus normal value, without statistically significant differences between the two groups $(\mathrm{p}=0.320)$. Frequency domain analysis showed the absence of physiologic decreased of LF in the night period in both cases and controls. The LF night in cases showed a statistically significant reduction when compared with controls $(\mathrm{p}=0.007)$.

\section{Discussion}

One third of our HIV-infected patients with known QTc prolongation measured by standard ECG recording showed a normal QTc interval when assessed by Holter ECG. Conversely, one fourth of our HIV-infected patients with a normal QTc interval measured by standard ECG had a prolonged QTc interval at Holter ECG. Beat-to-beat QTc interval measurements from 24-hour ECG recordings may provide additional information since cardiac autonomic nervous activity can modulate the variations of ventricular repolarization [18]. Data on variations of ventricular repolarization over time among HIV-infected patients are scanty [26].

In our patients, a significant relationship was found between duration of HIV infection and QTc interval prolongation. Such an association was previously reported by Charbit and coll [27]. The reasons for this relationship are 
Table 1 Demographic and clinical features of cases and controls

\begin{tabular}{|c|c|c|c|}
\hline Feature & $\begin{array}{c}\text { Cases } \mathrm{n}=32 \\
(\%)\end{array}$ & $\begin{array}{c}\text { Controls } n=64 \\
(\%)\end{array}$ & $p$ \\
\hline Gender M & $23(72 \%)$ & $46(72 \%)$ & 0.8 \\
\hline Age (years)* & $45.7 \pm 7.6$ & $45 \pm 9.9$ & 0.6 \\
\hline $\mathrm{BMI} \geq 25$ & $15(47 \%)$ & $22(34 \%)$ & 0.3 \\
\hline$<25$ & $17(53 \%)$ & $42(66 \%)$ & \\
\hline CDC stage $A+B$ & $22(69 \%)$ & $46(72 \%)$ & 0.9 \\
\hline$C$ & $10(31 \%)$ & $18(28 \%)$ & \\
\hline Years since HIV diagnosis* & $10.9 \pm 7.1$ & $7.8 \pm 6.4$ & 0.04 \\
\hline \multicolumn{4}{|l|}{ Risk factors for HIV infection } \\
\hline IVDU & $8(25 \%)$ & $10(16 \%)$ & 0.3 \\
\hline MSM & $7(22 \%)$ & $19(30 \%)$ & \\
\hline Eterosexual & $16(50 \%)$ & $35(54 \%)$ & \\
\hline other & $1(3 \%)$ & 0 & \\
\hline Arterial hypertension & $4(12 \%)$ & $13(20 \%)$ & 0.5 \\
\hline Current smokers & $18(56 \%)$ & $36(56 \%)$ & 0.8 \\
\hline Diabetes & 0 & 0 & \\
\hline Hypertriglyceridaemia & $7(22 \%)$ & $17(26 \%)$ & 0.8 \\
\hline Hypercholesterolaemia & $7(22 \%)$ & $18(28 \%)$ & 0.7 \\
\hline Alcohol abuse & $5(16 \%)$ & $3(5 \%)$ & 0.1 \\
\hline Familiarity for IHD & $10(31 \%)$ & $23(40 \%)$ & 0.8 \\
\hline Waist circumference $(\mathrm{cm})^{*}$ & $90.6 \pm 12.5$ & $87.0 \pm 10.0$ & 0.16 \\
\hline Hip circumference $(\mathrm{cm})^{*}$ & $97.3 \pm 10.4$ & $96.0 \pm 6.9$ & 0.5 \\
\hline Waist/hip ratio* & $0.93 \pm 0.07$ & $0.90 \pm 0.07$ & 0.05 \\
\hline Active drug abuse & $3(9 \%)$ & $3(5 \%)$ & 0.4 \\
\hline Methadone therapy & $2(6 \%)$ & $3(5 \%)$ & 1 \\
\hline $\begin{array}{l}\text { Prophylaxis with } \\
\text { cotrimoxazole }\end{array}$ & $3(9 \%)$ & $8(12 \%)$ & 0.7 \\
\hline Ongoing ART & $28(87 \%)$ & $53(83 \%)$ & 0.7 \\
\hline \multicolumn{4}{|l|}{ Type of ART } \\
\hline -Pl-based & $12(37 \%)$ & $26(41 \%)$ & 0.4 \\
\hline -NNRTI-based & $13(41 \%)$ & $25(39 \%)$ & \\
\hline-3 NRTI & $3(9 \%)$ & $2(3 \%)$ & \\
\hline HCV positive & $8(25 \%)$ & $12(19 \%)$ & 0.6 \\
\hline HBsAg positive & $1(3 \%)$ & $1(2 \%)$ & 1 \\
\hline $\mathrm{Na}(\mathrm{mEq} / \mathrm{L})^{*}$ & $139 \pm 3.2$ & $139 \pm 3.9$ & 1 \\
\hline $\mathrm{K}(\mathrm{mEq} / \mathrm{L})^{*}$ & $4,2 \pm 0.4$ & $4,3 \pm 0.3$ & 0.2 \\
\hline $\mathrm{Ca}(\mathrm{mg} / \mathrm{dL})^{*}$ & $9,2 \pm 0.6$ & $9,1 \pm 0.5$ & 0.4 \\
\hline CD4+ lymphocytes/mmc* & $501 \pm 214$ & $490 \pm 264$ & 0.8 \\
\hline \multicolumn{4}{|l|}{ HIVRNA (cp/mL) } \\
\hline$<50$ & $23(72 \%)$ & $45(70 \%)$ & 0.9 \\
\hline$\geq 50$ & $9(28 \%)$ & $19(30 \%)$ & \\
\hline QTc interval (ms)* & $475 \pm 33$ & $401 \pm 23$ & $<0.0001$ \\
\hline
\end{tabular}

Table 1 Demographic and clinical features of cases and controls (Continued)

\begin{tabular}{|c|c|c|c|}
\hline Ectopic ventricular beats & $13(41 \%)$ & $17(26 \%)$ & 0.2 \\
\hline Ectopic supraventricular beats & $14(44 \%)$ & $30(47 \%)$ & 0.9 \\
\hline
\end{tabular}

unclear, but could reflect the influence of chronic infection or cumulative exposure to anti-HIV drugs on the heart and the autonomic nervous system [27]. Indeed, autonomic neuropathy has been associated with QTc interval prolongation in HIV-infected patients [15] and asymptomatic alterations of the sympatho-vagal balance can occur at the early stage of the disease, although they are more severe in the advanced stage of HIV infection $[28,29]$. Moreover, a selective autonomic neuropathy has been associated to the adipose redistribution syndrome in HIV-infected patients [30]. The increased waist/hip ratio observed in our HIV-positive patients with QTc prolongation could suggest a link between autonomic dysfunction, lipodystrophy, and QTc prolongation.

In our study population, antiretroviral drugs were not significantly associated with QTc interval prolongation. However, patients receiving AZT had an increased risk of QTc interval prolongation (OR 2.27), although at a not statistically significant level. AZT has been shown to prolong the QT interval in rats by activating reactive oxygen species formation in the heart mitochondria [31]. Conversely, patients receiving FTC were less likely to have a QTc interval prolongation (OR 0.31); we did not find any work in the literature reporting an association between FTC and QTc interval alteration. The limited sample size could have influenced the lack of statistical significance in our findings.

Our group of HIV-infected patients with prolonged QTc showed at follow-up an increased risk of death when compared with patients with normal QTc $(\mathrm{p}=0.04)$. Interestingly, none of the patients died for heart-related diseases. Our data suggest a possible association between QTc prolongation and all-cause mortality also in HIV-infected patients, likewise previously described among other nonHIV populations [32].

The HRV analysis showed a sympathetic and parasympathetic dysfunction, as demonstrated by the reduction of global autonomic system (evaluated by SDNN value) and an impairment of parasympathetic component in night time with loss of circadian rhythms both in group of HIV-infected patients with and without QTc interval prolongation. However, in HIV-infected patients with QTc interval prolongation we observed a relative reduction in night time of LF spectral component (pseudo normalization) related to an impairment in sympathetic 
Table 2 Antiretroviral drugs and QTc prolongation

\begin{tabular}{|c|c|c|c|}
\hline Drug & Cases $(n=32)$ & Controls $(n=64)$ & $\mathrm{p}$ \\
\hline \multicolumn{4}{|c|}{ Zidovudine } \\
\hline Yes & 11 & 12 & 0.15 \\
\hline No & 21 & 52 & \\
\hline \multicolumn{4}{|c|}{ Lamivudine } \\
\hline Yes & 17 & 28 & 0.5 \\
\hline No & 15 & 36 & \\
\hline \multicolumn{4}{|c|}{ Tenofovir } \\
\hline Yes & 15 & 35 & 0.6 \\
\hline No & 17 & 29 & \\
\hline \multicolumn{4}{|c|}{ Emtricitabine } \\
\hline Yes & 4 & 20 & 0.08 \\
\hline No & 28 & 44 & \\
\hline \multicolumn{4}{|c|}{ Emtricitabine+tenofovir } \\
\hline Yes & 4 & 20 & 0.08 \\
\hline No & 28 & 44 & \\
\hline \multicolumn{4}{|c|}{ Zidovudine+lamivudine } \\
\hline Yes & 7 & 11 & 0.8 \\
\hline No & 25 & 53 & \\
\hline \multicolumn{4}{|c|}{ Didanosine } \\
\hline Yes & 4 & 4 & 0.4 \\
\hline No & 28 & 60 & \\
\hline \multicolumn{4}{|c|}{ Abacavir } \\
\hline Yes & 3 & 4 & 0.6 \\
\hline No & 29 & 60 & \\
\hline \multicolumn{4}{|c|}{ Efavirenz } \\
\hline Yes & 11 & 20 & 0.9 \\
\hline No & 21 & 44 & \\
\hline \multicolumn{4}{|c|}{ Nevirapine } \\
\hline Yes & 3 & 6 & 1 \\
\hline No & 29 & 58 & \\
\hline \multicolumn{4}{|c|}{ Atazanavir } \\
\hline Yes & 6 & 16 & 0.6 \\
\hline No & 26 & 48 & \\
\hline \multicolumn{4}{|c|}{ Fosamprenavir } \\
\hline Yes & 2 & 2 & 0.6 \\
\hline No & 30 & 62 & \\
\hline \multicolumn{4}{|c|}{ Lopinavir/ritonavir } \\
\hline Yes & 2 & 5 & 1 \\
\hline No & 30 & 59 & \\
\hline
\end{tabular}

modulation. We could hypothesize that in our study group of HIV-infected patients with QTc interval prolongation the longer duration of HIV infection could have a significant impact not only on parasympathetic cardiac regulation but also on sympathetic cardiac
Table 3 Indices of cardiovascular autonomic control

\begin{tabular}{lccc}
\hline & Cases (n=32) & Controls $(\mathbf{n}=\mathbf{6 4})$ & $\mathbf{p}$ \\
\hline LF/HF ratio & $2,78 \pm 1,08$ & $2,91 \pm 1,23$ & 0,306 \\
LF (n.u.) & $58,48 \pm 10,35$ & $60,73 \pm 9,68$ & 0,151 \\
HF (n.u.) & $31,10 \pm 7,43$ & $30,72 \pm 7,29$ & 0,404 \\
LF/HF ratio day & $3,26 \pm 1,25$ & $3,26 \pm 1,43$ & 0,491 \\
LF day (n.u.) & $62,91 \pm 10,81$ & $63,64 \pm 10,81$ & 0,378 \\
HF day (n.u.) & $26,85 \pm 7,69$ & $27,32 \pm 7,26$ & 0,385 \\
LF/HF ratio night & $1,90 \pm 1,06$ & $2,30 \pm 1,14$ & 0,050 \\
LF night (n.u.) & $50,30 \pm 12,94$ & $56,46 \pm 10,41$ & 0,007 \\
HF night (n.u.) & $38,76 \pm 9,45$ & $35,78 \pm 9,46$ & 0,077 \\
SDNN (ms) & $119,23 \pm 38,64$ & $122,93 \pm 34,92$ & 0,320 \\
SDNN day (ms) & $87,61 \pm 25,14$ & $97,26 \pm 41,00$ & 0,114 \\
SDNN night (ms) & $90,17 \pm 27,66$ & $104,22 \pm 30,52$ & 0,016 \\
RMSSD (ms) & $37,45 \pm 14,74$ & $40,49 \pm 16,22$ & 0,190 \\
RMSSD day (ms) & $36,16 \pm 18,25$ & $37,49 \pm 16,00$ & 0,358 \\
RMSSD night (ms) & $41,05 \pm 18,00$ & $43,23 \pm 20,38$ & 0,306 \\
\hline
\end{tabular}

Results are expressed as mean \pm SD for each variable. LF: low frequency; HF: high frequency; LF/HF: low frequency/high frequency; n.u.: normalized units; SDNN: standard deviation of all sinus rhythm RR intervals; RMSSD: the square root of the mean of the sum of the squares of differences between adjacent NN intervals; night time: 0-6 am, day time: $7 \mathrm{am}-11 \mathrm{pm}$.

component with a down regulation. We suggest that an accurate valuation of autonomic cardiac system in HIVinfected patients with a long duration of HIV infection could be advisable.

Our work presents some limitations: the number of patients in both groups is limited, and the statistical differences marginal; moreover, no echocardiographic data are provided. However, to the best of our knowledge, this seems to be the largest group of adult HIV-infected patients ever studied by 24-hour Holter ECG recording.

\section{Conclusion}

In conclusion, in our study group of HIV-infected patients the QTc interval prolongation was assessed by 24-hour Holter ECG recording and was associated with a longer duration of HIV infection and with a greater waist/hip ratio. Further studies are needed to clarify the role of antiretroviral drugs in the development of QTC interval prolongation when assessed by Holter ECG recording. Moreover, HIV-infected patients with QTc interval prolongation and with a longer duration of HIV infection were more likely to have an impairment of parasympathetic and sympathetic cardiac component.

\section{Abbreviations}

HIV: Human Immunodeficiency Virus; HCV: Hepatitis C Virus; HRV: Heart rate variability; SDNN: Standard deviation of normal-to-normal RR intervals; RMSSD: Square root of the mean of the sum of the squares of differences between adjacent NN intervals; VLF: Very low frequency; LF: Low frequency; HF: High frequency; ICC: Interclass correlation coefficient; AZT: Zidovudine;

FTC: Emtricitabine. 


\section{Competing interests}

NP received speaker's honoraria from Pfizer, MSD, Gilead, Novartis, Carefusion, Johnson \& Johnson, Bristol Myers Squibb, Sanofi Aventis. All other authors declare that they have no competing interests.

\section{Authors' contributions}

$A F, N P, L T$, and $P C$ conceived of the study, participated in its design and coordination and helped to draft the manuscript. SC, EB, and $P C$ registered the Holter-ECGs and helped to draft the manuscript. AF, ADS, LB, and LT read and interpreted the Holter-ECGs, and drafted and revised the manuscript. All authors read and approved the final manuscript.

\section{Author details}

${ }^{1}$ U.O. Geriatria, Ospedale di Montefiascone, via Donatori di sangue, Montefiascone 01027, Italy. ${ }^{2}$ Second Infectious Diseases Unit, National Institute for Infectious Diseases "L. Spallanzani", via Portuense 292, Rome 00149, Italy. ${ }^{3}$ Dipartimento di Medicina Clinica, Policlinico, "Umberto I", UOS Diagnostica Cardiovascolare Internistica Integrata, viale del Policlinico 155, Rome 00161, Italy.

Received: 9 August 2012 Accepted: 19 December 2012 Published: 23 December 2012

\section{References}

1. Kocheril AG, Bokhari SAJ, Batsford WP, Sinusas AJ: Long QTC and torsades de pointes in human immunodeficiency virus disease. PACE 1997 20(11):2810-2816.

2. Sani MU, Okeahialam BN: QTc interval prolongation in patients with HIV and AIDS. J Natl Med Assoc 2005, 97(12):1657-1661.

3. Nordin C, Kohli A, Beca S, Zaharia V, Grant T, Leider J, Marantz P: Importance of hepatitis C coinfection in the development of QT prolongation in HIV-infected patients. J Electrocardiol 2006, 39(2):199-205.

4. Reinsch N, Buhr C, Krings $P$, Kaelsch $H$, Neuhaus $K$, Wieneke $H$, Erbel R Neumann T: Prevalence and risk factors of prolonged QTc interval in HIVinfected patients: results of the HIV-HEART study. HIV Clin Trials 2009, 10(4):261-268

5. Eisenhauer MD, Eliasson AH, Taylor AJ, Coyne PE Jr, Wortham DC: Incidence of cardiac arrhythmias during intravenous pentamidine therapy in HIVinfected patients. Chest 1994, 105(2):389-395.

6. von Seidlein L, Jaffar S, Greenwood B: Prolongation of QTc interval in African children treated for falciparum malaria. Am J Trop Med Hyg 1997 56(5):494-497.

7. Lopez JA, Harold JG, Rosenthal MC, Oseran DS, Schapira JN, Peter T: QT prolongation and torsades de pointes after administration of trimethoprim-sulfamethoxazole. Am J Cardiol 1987, 59(4):376-377.

8. Gil M, Sala M, Anguera I, Chapinal O, Cervantes M, Guma JR, Segura F: QT prolongation and torsades de pointes in patients infected with human immunodeficiency virus and treated with methadone. Am J Cardiol 2003, 92(8):995-997.

9. Vallejo Camazon N, Rodriguez Pardo D, Sanchez Hidalgo A, Tornos Mas MP, Ribera E, Soler Soler J: Ventricular tachycardia and long QT associated with clarithromycin administration in a patient with HIV infection. ReV Esp Cardiol 2002, 55(8):878-881.

10. Flanagan MC, Mitchell ES, Haigney MC: Ciprofloxacin-induced torsade de pointes. Int J Cardiol 2006, 113(2):239-241.

11. Prabhakar M, Krahn AD: Ciprofloxacin-induced acquired long QT syndrome. Heart Rhythm 2004, 1(5):624-626.

12. Castillo R, Pedalino RP, El-Sherif N, Turitto G: Efavirenz-associated QT prolongation and Torsade de Pointes arrhythmia. Ann Pharmacother 2002 36(6):1006-1008

13. Anson BD, Weaver JG, Ackerman MJ, Akinsete $\mathrm{O}$, Henry $\mathrm{K}$, January $C T$, Badley AD: Blockade of HERG channels by HIV protease inhibitors. Lancet 2005, 365(9460):682-686

14. Ly T, Ruiz ME: Prolonged QT interval and torsades de pointes associated with atazanavir therapy. Clin Infect Dis 2007, 44(6):e67-e68.

15. Villa A, Foresti $V$, Confalonieri F: Autonomic neuropathy and prolongation of QT interval in human immunodeficiency virus infection. Clin Auton Res 1995, 5(1):48-52

16. Freeman R, Roberts MS, Friedman LS, Broadbridge C: Autonomic function and human immunodeficiency virus infection. Neurology 1990, 40(4):575-580.
17. Lane RD, Zareba W, Reis HT, Peterson DR, Moss AJ: Changes in ventricular repolarization duration during typical daily emotion in patients with long QT syndrome. Psychosom Med 2011, 73(1):98-105.

18. Bonnemeier H, Wiegand UK, Braasch W, Brandes A, Richardt G, Potratz J: Circadian profile of QT interval and QT interval variability in 172 healthy volunteers. Pacing Clin Electrophysiol 2003, 26(1Pt2):377-382.

19. Piotrovsky $\mathrm{V}$ : Pharmacokinetic-pharmacodynamic modelling in the data analysis and interpretation of drug-induced QT/QTc prolongation. AAPS J 2005, 7(3):E609-E624.

20. Schouten EG, Dekker JM, Meppelink P, Kok FJ, Vandenbroucke JP, Pool J: QT interval prolongation predicts cardiovascular mortality in an apparently healthy population. Circulation 1991, 84(4):1516-1523.

21. Moss AJ: Measurement of the QT interval and the risk associated with QTc in interval prolongation: a review. Am J Cardiol 1993, 72(6):23B-25B.

22. The Expert Panel: Third report of the national cholesterol education program (NCEP) expert panel on detection, evaluation, and treatment of high blood cholesterol in adults (adult treatment panel III). final report. Circulation 2002, 106(25):3143-3421.

23. Saitz R: Unhealthy alcohol use. N Engl J Med 2005, 352(6):596-607.

24. Task Force of the European Society of Cardiology and the North American Society of Pacing and Electrophysiology: Heart rate variability: standards of measurement, physiological interpretation and clinical use. Circulation 1996, 93(5):1043-1065.

25. Chinello P, Lisena FP, Angeletti C, Boumis E, Papetti F, Petrosillo N: Role of antiretroviral treatment in prolonging QTc interval in HIV-positive patients. J Infect 2007, 54(6):597-602.

26. Benchimol-Barbosa PR: Circadian cardiac autonomic function in perinatally HIV-infected preschool children. Braz J Med Biol Res 2009, 42(8):722-730

27. Charbit B, Rosier A, Bollens D, Boccara F, Boelle PY, Koubaa A, Girard PM, Funck-Brentano C: Relationship between HIV protease inhibitors and QTC interval duration in HIV-infected patients: a cross-sectional study. $\mathrm{Br} J$ Clin Pharmacol 2009, 67(1):76-82

28. Becker K, Gorlach I, Frieling T, Haussinger D: Characterization and natural course of cardiac autonomic nervous dysfunction in HIV-infected patients. AIDS 1997, 11(6):751-757.

29. Mittal CM, Wig N, Mishra S, Deepak KK: Heart rate variability in human immunodeficiency virus-positive individuals. Int J Cardiol 2004, 94(1):1-6.

30. Fliers E, Sauerwein HP, Romijn JA, Reiss P, van der Valk M, Kalsbeek A, Kreier F, Buijs RM: HIV-associated adipose redistribution syndrome as a selective autonomic neuropathy. Lancet 2003, 362(9397):1758-1760.

31. Szabados E, Fisher GM, Toth K, Csete B, Nemeti B, Trombitas K, Habon T, Endrei $D$, Sumegi $B$ : Role of reactive oxygen species and poly-ADP-ribose polymerase in the development of AZT-induced cardiomyopathy in rat. Free Radic Biol Med 1999, 26(3-4):309-317.

32. Williams ES, Thomas KL, Broderick S, Shaw LK, Velazquez EJ, Al-Khatib SM, Daubert JP: Race and gender variation in the QT interval and its association with mortality in patients with coronary artery disease: results from the Duke Databank for Cardiovascular Disease (DDCD). Am Heart J 2012, 164(3):434-441.

doi:10.1186/1471-2261-12-124

Cite this article as: Fiorentini et al:: QTc interval prolongation in HIVinfected patients: a case-control study by 24-hour Holter ECG recording. BMC Cardiovascular Disorders 2012 12:124.

\section{Submit your next manuscript to BioMed Central and take full advantage of:}

- Convenient online submission

- Thorough peer review

- No space constraints or color figure charges

- Immediate publication on acceptance

- Inclusion in PubMed, CAS, Scopus and Google Scholar

- Research which is freely available for redistribution 